\title{
Educating employers to make an informed choice about financial education
}

Received: 23rd May, 2005

\section{Vaughan Jenkins}

is a freelance writer and marketing consultant. With experience across a wide variety of financial services, Vaughan has developed a particular interest in the potential for workplace marketing in the UK and the need for the financial education of consumers. He has produced a number of articles and presentations on workplace marketing and retirement planning. He holds a BA from Nottingham University and an MA from London University/LSE in economic history.

\begin{abstract}
The workplace has become the centre stage in the debate on how the UK can bridge the 'Savings Gap'. It would appear that there is consensus amongst interested parties that the workplace is the channel through which their ambitions can be mutually satisfied. Employees appear to respect and value the employer as a source of information and advice; financial services providers see the attraction of collective selling in a margin constrained world and Government sees that its policy objective of reducing state dependency can be realised via public and private sector employers. The missing link has been the incentive for employers to voluntarily support financial education, particularly if it extends beyond the existing benefits on offer. Cost concerns and regulatory restrictions have constrained all but the most philanthropic employers.

This paper suggests that evidence from small scale studies in the USA shows that there is a direct correlation between financially 'de-stressed' employees and productivity gains. This linkage from financial education to financial performance may be the incentive required to encourage employers to be supportive, particularly when integrated with Government campaigns and regulatory change. Whilst further research in the UK environment is required, this might be an attractive alternative to corporate tax relief or other costly and complex inducements to employers.
\end{abstract}

Keywords: financial education; financial planning; workplace marketing; employer attitudes; stress at work

Vaughan Jenkins Tel: +44 (0)797 1151174; e-mail: vaughan@caversham 75.freeserve.co.uk

\section{Introduction}

In the wake of Adair Turner's interim report on the state of the nation's retirement provision, there have been repeated comments about consumer apathy and the need to incentivise employers to provide financial education. That employers represent an essential part of the solution is widely agreed upon but how and, indeed, precisely why they should act seems to be more controversial. In lean and mean cost-cutting times, with finance directors increasingly holding the whip hand over human resource decisions, the case for indulging employees' request for financial guidance has not been compelling. This has been reinforced by genuine concerns about straying into regulated advice and facing unwelcome liabilities. Whilst the government has been taking steps to alleviate some of the concerns, through 
exemptions and additional employer guidelines on generic versus individual advice, the financial education of employees is not a high priority for most employers. One of the key barriers to workplace-based development, perhaps the missing link appears to be the inability of employers to measure the benefit of benefits in general but this has not been a prominent feature of the debate. If tangible returns on the investment in financial education could be demonstrated, employers may be far more willing to facilitate and promote it, even without additional state incentives.

\section{Evaluating financial education}

Many investments in people tend to be viewed as either hard to measure or just overly expensive to quantify and may therefore be made on a me-too basis. Evaluating financial education is not exceptional in this respect. Support for the benefit of employee benefits tends to rest on the retention, recruitment and motivation of employees and their talents. In practice, little or no effort is made to correlate benefits provision with these desired outcomes. The tendency has been instead to benchmark benefit packages against specific competitors or sector averages with little regard to cost/benefit analysis. This situation changed markedly when the cost of defined benefit (DB) pension promises emerged and has had some knock-on effects. The cost of benefits has become a much higher priority and HR decisions have come under more direct scrutiny from finance directors and CEOs. The pressure to manage costs means that benefits are now seen as necessary evils. If anything, employer attitudes against financial education seem to have hardened witness the difficulty of recruiting firms into Department of Work and Pensions (DWP) experiments, for example.
Almost two out of three organisations offer no access to financial planning for their employees. ${ }^{1}$ Less than 10 per cent offer full financial planning with the rest providing pension advice throughout membership of a pension scheme or at retirement. Of those offering advice nearly 80 per cent made referrals to IFAs whilst just 10 per cent offered some form of web-based financial planning tool. Clearly, this flies in the face of the government's ambitions to see employers play a greater part in closing the savings gap and supporting the DWP's Informed Choice initiative.

The current antidote seems to consist of either relaxing rules constraining employers in relation to pensions or else imposing new obligations. The former certainly includes changes arising from the recent Financial Services and Markets Act two-year anniversary review (commonly known as FSMA +2). Employers faced some anomalies in relation to pension related-issues. Stakeholder pensions fell within the FSMA's regime unlike occupational schemes and employee share schemes. The Treasury has now harmonised the situation by exempting group personal pensions and stakeholder pensions schemes on condition that employers are making a contribution to the pensions they are promoting and that they declare the size and nature of their contributions. Employers will also have to ensure that they gain no direct financial benefit from the promotions and they are discouraged from providing individual advice, referring employees instead to an FSA-authorised firm. The government's provision of a $£ 150$ tax exemption per employee per year for one-to-one sessions on financial advice and external seminars aims to make such advice more accessible. Given the move towards contract-based defined contribution (DC) arrangements these changes are to be welcomed even if they only reward proactive and benign 
employers. The Treasury has also reserved judgment on extending the exemption beyond pensions to other work-related investment and insurance products, giving some encouragement to financial services providers exploring workplace marketing opportunities.

Other measures include mandatory access to information where employer pension contributions are below a given threshold, effectively attempting to shame employers into having to explain why they are not making larger contributions. There was also a debate around the practice of auto-enrolment in 2004, with some seeing this as a palatable form of 'soft compulsion'. Many firms already practise this method and the National Association of Pension Funds (NAPF) monitors employee participation levels between schemes with and without auto-enrolment - the difference appearing to be about 30 per cent in favour of the former. Employers convinced of the benefit of employer contributions will pursue this route whilst those that see pensions participation as just a cost will refrain (or as Abraham Lincoln put it 'For those who like this sort of thing, this is the sort of thing they like'). There have been hints that further pensions legislation, including auto-enrolment, could be forthcoming and this element seems to have cross-party support.

\section{Future developments}

Research and anecdotal evidence suggest that many employers, including some of the very largest, either have weak measures of the value of benefits or none at all. Some recent surveys illustrate the gap in employer knowledge. The Jardine Lloyd Thompson 'Reward and Benefits Survey 2004' found that nearly 60 per cent of respondents' firms did not even know what their benefits spend was as a percentage of payroll. Nearly

three-quarters did not have a defined reward and benefit strategy with most (48 per cent) basing their offering on market rates. Perversely, a study by the Work Foundation and Employee Benefits magazine $^{2}$ found that the higher the percentage of payroll spent on benefits, the less likely it was that the return on investment (ROI) would be measured. Overall only 9 per cent of respondents made any attempt to calculate an ROI on benefits and even then the quality of the effort was questionable. To cap it all, nearly half of respondents felt that their benefit packages were outdated and in need of overhaul, perhaps adding fuel to cost cutting drives.

If there is a poor line of sight from benefit investment to business gain and evidence of employer dissatisfaction with their proposition to employees, it is surely an ideal time for government and employers to reassess and quantify financial education as a benefit. The incentives and punishments of current policy changes, however, seem unlikely to change the status quo of the hearts and minds of employers. But there is a third way available - building a business case for benefit provision and specifically financial education, based on productivity gains to the employer and with several other benefits as by-products

A small but enlightening US research study $^{3}$ published at the beginning of 2004 measured the degree of financial stress within a group of white-collar workers. It was found that stressed individuals were not only less satisfied employees but were more likely to be absent and spent 26 per cent more work time than the average sorting out their personal financial issues. Other earlier studies ${ }^{4}$ have highlighted the negative impact of poor personal financial wellness on employers, ie low engagement and poor productivity. 
Another small scale survey in $2003^{5}$ demonstrated how a financial planning seminar and one-to-one counselling had a profound effect upon participants. Nearly three-quarters felt more confident in managing their money to achieve financial security and about two-thirds reported that they felt that they were in better control of their personal finances. Remember that financial stress is by no means confined to the low income, poorly educated segments of the workforce. Alarmingly, researchers have suggested that as many as $15-20$ per cent of US workers could be categorised as financially stressed, making the size of the potential return very attractive to employers. Mapping this de-stressing of individuals to the potential productivity gains suggested in the other studies therefore makes a strong business case for employers to encourage financial education in the workplace.

There are signs that US employers at least are beginning to get the message. Whilst the majority provide financial education for the more traditional philanthropic and paternalistic reasons, just over half in a recent Ernst and Young survey ${ }^{6}$ agreed that they provided it to improve productivity by reducing financial stress with 83 per cent of employers providing some form of financial education. But what sort of financial education could or should be provided?

The message from the US market, setting aside a debate on the quality of the financial education offered, is really quite mixed. There is a growing sense that employees require a holistic approach to financial planning (not just pension scheme booklets and fact sheets) if the potential productivity gains are going to be realised. At the same time, 401(k) providers frustrated by unproductive investments in communications and web tools are declaring the shortcomings of an educational approach. Better to change behaviour first through auto-enrolment and the autopilot style schemes (with automatic contribution increases and portfolio balancing etc) and safe harbour investments that immunise the employee from detriment. If the only measures of success are plan participation and contribution levels then this enforced approach is clearly effective. This is unlikely, however, to positively impact employees' financial education and the productivity gains that this may bring. An analogy might be found in the old proverb: 'Give a man a fish and you feed him for a day. Teach a man to fish and you feed him for a lifetime'. Working from the premise that employee consumers are too apathetic and ignorant to educate themselves, or at best will find it too time consuming, is likely to produce a society of financial automatons rather than self-directed, financially literate citizens, capable of making informed choices. Suggesting that financial education was tried once and it did not work is too simplistic and shortsighted. There is instead every opportunity for employers and providers to blend the automated and the educational approaches and the UK has the chance to learn from US experience.

A focus on employee needs and the stress created by financial issues appears to be in stark contrast to the approach taken by many product providers in the UK workplace market. The focus of pension providers is on asset accumulation, particularly in the DC market and employee communications are often almost wholly centred on investment topics, especially fund choice. Whilst there have been great improvements in delivering 'plain English' guides, even these often contain examples of assumed knowledge and pay scant attention to the broader context of personal money management. Even 
fewer, in my experience, are based on the principles of adult education.

The breadth and sophistication of the educational proposition needs to be segmented according to the employee audience, from basic money management through to complex retirement planning. This can be organised around a core resource containing factual information on state benefits, tax and allowances etc, with educational material branching out to specific topics eg protection, debt, risk and return etc. Online services can be geared to the preferences of individual employees enabling the content to be pitched to the users' level. These could include items such as the DWP's retirement planning tool due to be launched in 2006 or the Pre-Retirement Association's www.learnaboutmoney.org site, which provides a comprehensive but free basic financial planning guide. This can then be supplemented by other online and offline facilities from 'webinars' and traditional seminars through to workbooks, personal counselling and access to regulated advice (face to face or by telephone). The profile of the workforce will determine the mix of resources to be provided, based on initial research into the financial stress being experienced and the potential return on investment.

Whilst the solution that could be offered could easily comprise of a partnership between employer, provider, government and not-for-profit sector resources, more needs to be done to establish the proof of concept. The US studies have been small scale and the cultural, social and economic conditions differ to those found here. So far, I have failed to find a similar study in the UK. Whilst there is much discussion about anxiety and absenteeism in the workplace, there seems to be a need for some valuable research to confirm and quantify the causal link between stress related to personal finances and productivity. This could be used to educate employers on the benefit of financial education and to help a more scientific, quantitative approach to the benefit of the benefits offered to employees.

\section{References}

1 The Defined Contribution Industry Survey 2004. J P Morgan Fleming Asset Management. Based on 155 respondents including 93 of the top 350 private sector pension funds.

2 'The Benefits Book, 2004', Employee Benefits.

3 Kim, J. and Garman, E. T. (2004) 'Financial stress, pay satisfaction and workplace performance', Financial Education, Jan/Feb.

4 Garman, E. T., Leech, I. E., and Grable, J. E. (1996) 'The negative impact of employee poor personal financial behaviours on employers', Financial Counseling and Planning, Vol. 7, pp. 157-168. Joo, S and Garman, E. T. (1998) 'Personal financial wellness may be the missing factor in understanding and reducing worker absenteeism', Personal Finances and Worker Productivity, Vol. 2, No. 2, pp. 172-182.

5 Kim, J. and Garman, E. T. (2003) 'Financial education and advice changes worker attitudes and behaviours' Journal of Compensation and Benefits, Vol 19, No. 5, pp. 7-13, September/October.

6 Study conducted by Emst \& Young LLP and ExecuNet, News Release, 18 November, 2004. 